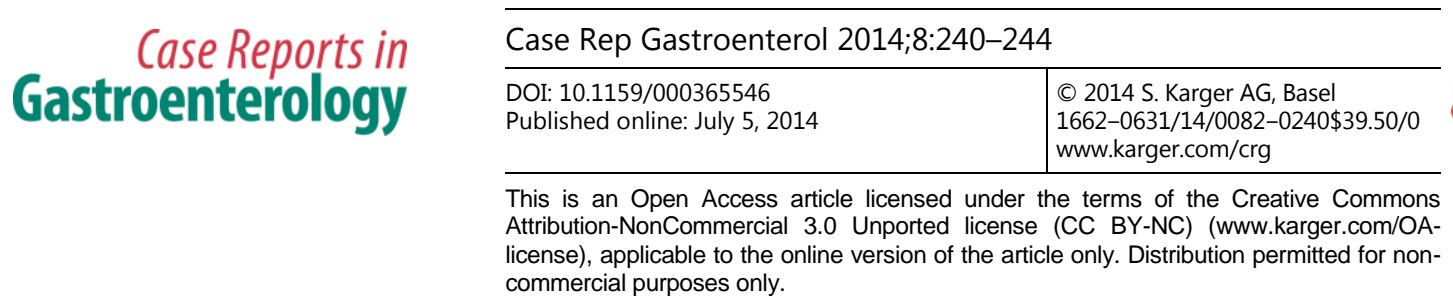
commercial purposes only.

\title{
Severe Colitis Associated with both Epstein-Barr Virus and Cytomegalovirus Reactivation in a Patient with Severe Aplastic Anemia
}

\author{
Hiroshi Matsumoto ${ }^{a}$ Yoshiki Kimura $^{a}$ Takahisa Murao $^{a}$ \\ Motoyasu Osawa $^{a}$ Takashi Akiyama $^{\mathrm{b}}$ Kiyohito Mannojic \\ Risa Koresawa ${ }^{c}$ Hirotoshi Tokunaga $^{c}$ Hideho Wada $^{c}$ \\ ${\text { Takashi Sugiharac }{ }^{c} \text { Ken Haruma }}^{a}$ \\ ${ }^{a}$ Department of Gastroenterology, Division of Medicine, ${ }^{b}$ Department of Pathology and \\ 'Department of Hematology, Division of Medicine, Kawasaki Medical School, Kurashiki, \\ Japan
}

\section{Key Words}

Epstein-Barr virus · Cytomegalovirus · Colitis · Aplastic anemia

\begin{abstract}
Epstein-Barr virus (EBV) and cytomegalovirus (CMV) are members of the herpesvirus family and common causes of viral infection in humans. CMV infection of the gastrointestinal tract occurs mainly in immunocompromised individuals, on the other hand EBV infection and reactivation involving the gastrointestinal tract is very rare. A 56-year-old man was diagnosed with severe aplastic anemia and treated with antithymocyte globulin (ATG) and cyclosporine (CSP). After 2 years of ATG/CSP therapy, he suddenly started passing bloody diarrhea and developed a high fever despite CSP treatment. Endoscopic features included severe edema and multiple superficial ulcers; the patient was initially diagnosed with severe colitis resembling inflammatory bowel disease (IBD). However, his symptoms did not resolve with steroid treatment. Immunohistochemical analysis of samples obtained from a second colonoscopy showed cells positive for CMV, and in situ hybridization revealed EBV-encoded small RNA-1positive cells. Additionally, the patient's serum was positive for C7-HRP, and both blood and colon tissues were positive for EBV DNA, which was detected using PCR analysis. We finally diagnosed the patient with colitis associated with reactivation of both CMV and EBV. The patient remains diarrhea-free after 1.5 years with scheduled globulin treatment and after cessation of immunosuppressive drug therapy. To our knowledge, this is the first reported
\end{abstract}


Matsumoto et al.: Severe Colitis Associated with both Epstein-Barr Virus and

Cytomegalovirus Reactivation in a Patient with Severe Aplastic Anemia

case of an immunodeficient patient with severe hemorrhagic colitis that was associated with reactivation of both EBV and CMV, and whose endoscopic findings mimicked IBD.

(C) 2014 S. Karger AG, Basel

\section{Introduction}

Epstein-Barr virus (EBV) and cytomegalovirus (CMV) are members of the herpesvirus family. Co-infection with these two viruses occurs occasionally in children, but co-reactivation of these viruses has not been reported. EBV is a double-stranded DNA herpesvirus that infects and persists in $>90 \%$ of humans worldwide [1]. EBV infection frequently causes self-limiting infectious mononucleosis; latent infection is preferentially sustained in B cells over the lifetime of the host [2]. EBV infection and reactivation involving the gastrointestinal tract is very rare. CMV is also a common viral infection in humans, which occurs in $40-100 \%$ of humans worldwide [3]. Primary CMV infection is followed by either chronic infection or viral latency from which the virus may be reactivated. CMV infection of the gastrointestinal tract occurs mainly in immunocompromised individuals, including those with inflammatory bowel disease (IBD) and those who have received transplants.

We herein report, to our knowledge, the first case of an immunodeficient patient with severe hemorrhagic colitis associated with the reactivation of both EBV and CMV, and whose endoscopic findings mimicked IBD.

\section{Case Report}

A 56-year-old man was diagnosed with severe aplastic anemia (SAA), showing pancytopenia and severe bone marrow hypocellularity; therefore, he was treated with antithymocyte globulin (ATG) and cyclosporine (CSP). After 2 years of ATG/CSP therapy, he suddenly started passing bloody diarrhea and developed a high fever. Blood tests revealed the following results: hemoglobin level $4.2 \mathrm{~g} / \mathrm{dl}$, platelet count $3.7 \times 10^{4}$ cells/l, and white blood cell count 3,230 cells/l. The patient's C-reactive protein level was $4.7 \mathrm{mg} / \mathrm{dl}$ and serum CMV antigen C7-HRP was positive in 2/50,000 cells. Stool cultures showed no bacterial infection. Colonoscopy revealed severe edema and multiple superficial ulcers (fig. 1a). The patient was diagnosed with severe colitis resembling IBD. Histopathological analysis of the biopsy specimen revealed non-specific inflammation (fig. 2a). We initially thought the colitis to be associated with CMV infection because of the endoscopic features and positive result for serum CMV antigen in spite of negative results obtained using immunohistochemical analysis. Therefore, the patient was treated with ganciclovir for 2 weeks; however, his symptoms did not resolve. As the colitis was similar to IBD, the patient received secondary steroid therapy. However, his symptoms persisted for the next 2 weeks. Therefore, assuming a potential misdiagnosis, a second colonoscopy was performed, which showed multiple deep ulcerations (fig. 1b). Immunohistochemical analysis of colonic biopsy samples revealed CMVpositive cells (fig. 2b), and in situ hybridization revealed EBV-encoded small RNA-1 (EBER-1)-positive cells (fig. 2c). Additionally, serum C7-HRP was positive in 33/50,000 cells, and both blood and colon tissues were positive for EBV DNA, which was detected using PCR analysis. We finally diagnosed the patient with colitis associated with the reactivation of CMV and EBV. Retrospective analysis of the first colonic biopsy samples also showed EBER-1-positive cells. After cessation of CSP and treatment with gamma globulin and ganciclovir, his symptoms resolved. Follow-up colonoscopy after 3 months showed multiple 
Matsumoto et al.: Severe Colitis Associated with both Epstein-Barr Virus and

Cytomegalovirus Reactivation in a Patient with Severe Aplastic Anemia

ulcer scars. A subsequent blood sample was negative for EBV DNA, and colon cells were negative for EBER-1, but positive for EBV DNA.

Interestingly, 6 months after the first remission, the patient had a recurrence of severe bloody diarrhea after an increase in the CSP dose. Both blood and colon tissues were positive for EBV DNA and a colon biopsy showed EBER-1-positive cells; however, we did not detect CMV reactivation. After a second round of treatment with gamma globulin and ganciclovir and cessation of CSP, his symptoms resolved. The patient has had no abdominal symptoms for 1.5 years with the scheduled antiviral treatments and after cessation of CSP.

\section{Discussion}

To our knowledge, this is the first reported case of severe colitis associated with reactivation of both EBV and CMV in a patient with SAA after ATG/CSP therapy. EBV primary infected B cells, CMV was designed to enter monocytes besides lymphocytes, whereas both of them also infected epithelial cells [4]. Reactivation of EBV or CMV after ATG/CSP therapy has been reported in patients with SAA [1, 2]. After ATG/CSP therapy in patients with SAA, EBV reactivation occurred in $87 \%$ and $\mathrm{CMV}$ reactivation in 33\% [5]. However, reactivation of both these viruses has not been reported, and the clinical features are not well known.

In this case, we have several reasons to associate EBV with the severe colitis: the serum samples from the patient were positive for EBV DNA and the colonic tissue showed the presence of EBER-1-positive cells on in situ hybridization. In contrast, at the time of colitis remission, neither EBV DNA in the blood nor EBER-1-positive cells in the colon were detected. Interestingly, the patient had two colitis attacks with identical clinical symptoms and EBV results. Therefore, colitis likely reflects EBV reactivation, which is indicated by the presence of EBV DNA in the blood and EBER-1-positive cells in the colon. There is only one report of EBV colitis after ATG therapy [6], however EBV and CMV colitis after ATG therapy have never been reported.

In the case of this patient, it was necessary to distinguish severe colitis from other EBVassociated diseases, including chronic active EBV infection, EBV-associated T/natural killer cell lymphoproliferative disorder (EBV-T/NK-LPD) and EBV-associated lymphomagenesis. This case did not satisfy chronic active EBV infection guidelines for diagnosis of lymphomagenesis [6, 7]. EBV-T/NK-LPD has 4 categories: A1, A2, A3 and B [5]. Ohshima et al. [8] reported that EBV-T/NK-LPD could develop into category A1 (smoldering), A2 (chronic) or A3 (leukemia/lymphoma). Our patient was successfully treated twice with antiviral drugs only and after cessation of CSP treatment and without the use of chemotherapy such as rituximab. In addition, he had no recurrence of symptoms for 1.5 years after treatment. Therefore, this case was considered category A1, i.e. smoldering EBV-T/NK-LPD. However, careful follow-up is necessary as colitis is not a well-known symptom of EBV-T/NK-LPD.

There have been some reports of EBV/CMV infection in patients with IBD [9-11]. Those studies used PCR analysis to show the presence of EBV in gastrointestinal tissue from patients with IBD. However, these reports never used immunohistochemical analysis or tested blood samples to detect the presence of EBV DNA. Weinberg et al. [12] reported the difficulty of differentiating between EBV-associated diarrhea and IBD. Besides, the mechanisms of ulcer formation and the differences in endoscopic features caused by EBV are not well understood. In the future, more case studies are necessary to differentiate EBV-associated intestinal diseases from IBD in patients with EBV infections.

In conclusion, to our knowledge, this is the first reported case of a patient with SAA who developed severe hemorrhagic colitis owing to the reactivation of both EBV and CMV. 


\begin{tabular}{l|l}
\hline \multicolumn{2}{l}{ Case Rep Gastroenterol 2014;8:240-244 } \\
\hline DOI: 10.1159/000365546 & $\begin{array}{l}\text { C 2014 S. Karger AG, Basel } \\
\text { www.karger.com/crg }\end{array}$ \\
\hline
\end{tabular}

Matsumoto et al.: Severe Colitis Associated with both Epstein-Barr Virus and Cytomegalovirus Reactivation in a Patient with Severe Aplastic Anemia

\title{
Disclosure Statement
}

\author{
No conflict of interest exists.
}

\section{References}

1 Cohen JI: Epstein-Barr virus infection. N Engl J Med 2000;343:481-492.

-2 Luzuriaga K, Sullivan JL: Infectious mononucleosis. N Engl J Med 2010;362:1993-2000.

-3 Galiatsatos P, Shrier I, Lamoureux E, Szilagyi A: Meta-analysis of outcome of cytomegalovirus colitis in immunocompetent hosts. Dig Dis Sci 2005;50:609-616.

4 Scheinberg P, Fischer SH, Li L, Nunez O, Wu CO, Sloand EM, Cohen JI, Young NS, John Barrett A: Distinct EBV and CMV reactivation patterns following antibody-based immunosuppressive regimens in patients with severe aplastic anemia. Blood 2007;109:3219-3224.

5 Grinde B: Herpesvirus: latency and reactivation - viral strategies and host response. J Oral Microbiol 2013;25:5.

-6 Sugimoto-Sekiguchi H, Tashiro H, Shirasaki R, Arai T, Yamamoto T, Oka Y, Akiyama N, Kawasugi K, Shirafuji $\mathrm{N}$ : Colonic EBV-associated lymphoproliferative disorder in a patient treated with rabbit antithymocyte globulin for aplastic anemia. Case Rep Gastrointest Med 2012;2012:395801.

7 Okano M, Kawa K, Kimura H, Yachie A, Wakiguchi H, Maeda A, Imai S, Ohga S, Kanegane H, Tsuchiya S, Morio T, Mori M, Yokota S, Imashuku S: Proposed guidelines for diagnosing chronic active Epstein-Barr virus infection. Am J Hematol 2005;80:64-69.

-8 Ohshima K, Kimura H, Yoshino T, Kim CW, Ko YH, Lee SS, Peh SC, Chan JK; CAEBV Study Group: Proposed categorization of pathological states of EBV-associated T/natural killer-cell lymphoproliferative disorder (LPD) in children and young adults: overlap with chronic active EBV infection and infantile fulminant EBV T-LPD. Pathol Int 2008;58:209-217.

-9 Linton MS, Kroeker K, Fedorak D, Dieleman L, Fedorak RN: Prevalence of Epstein-Barr virus in a population of patients with inflammatory bowel disease: a prospective cohort study. Aliment Pharmacol Ther 2013;38: 1248-1254.

10 Ryan JL, Shen YJ, Morgan DR, Thorne LB, Kenney SC, Dominguez RL, Gulley ML: Epstein-Barr virus infection is common in inflamed gastrointestinal mucosa. Dig Dis Sci 2012;57:1887-1898.

-11 Magro F, Santos-Antunes J, Albuquerque A, Vilas-Boas F, Macedo GN, Nazareth N, Lopes S, Sobrinho-Simões J, Teixeira S, Dias CC, Cabral J, Sarmento A, Macedo G: Epstein-Barr virus in inflammatory bowel disease correlation with different therapeutic regimens. Inflamm Bowel Dis 2013;19:1710-1716.

12 Weinberg I, Neuman T, Margalit M, Ayman F, Wolf DG, Ben-Yehuda A: Epstein-Barr virus-related diarrhea or exacerbation of inflammatory bowel disease: diagnostic dilemma. J Clin Microbiol 2009;47:1588-1590.
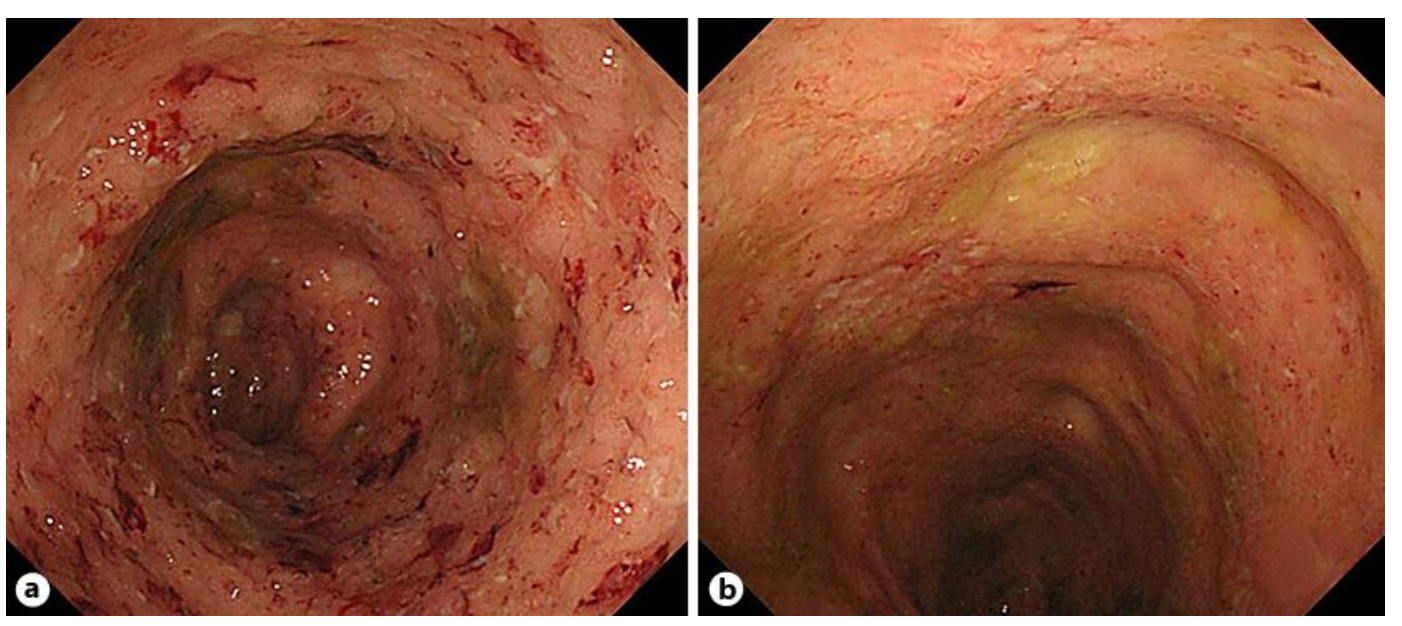

Fig. 1. Endoscopic images. Colonoscopy performed at admission revealed multiple erosions and edema (a) and round ulcerations (b). 
Matsumoto et al.: Severe Colitis Associated with both Epstein-Barr Virus and Cytomegalovirus Reactivation in a Patient with Severe Aplastic Anemia
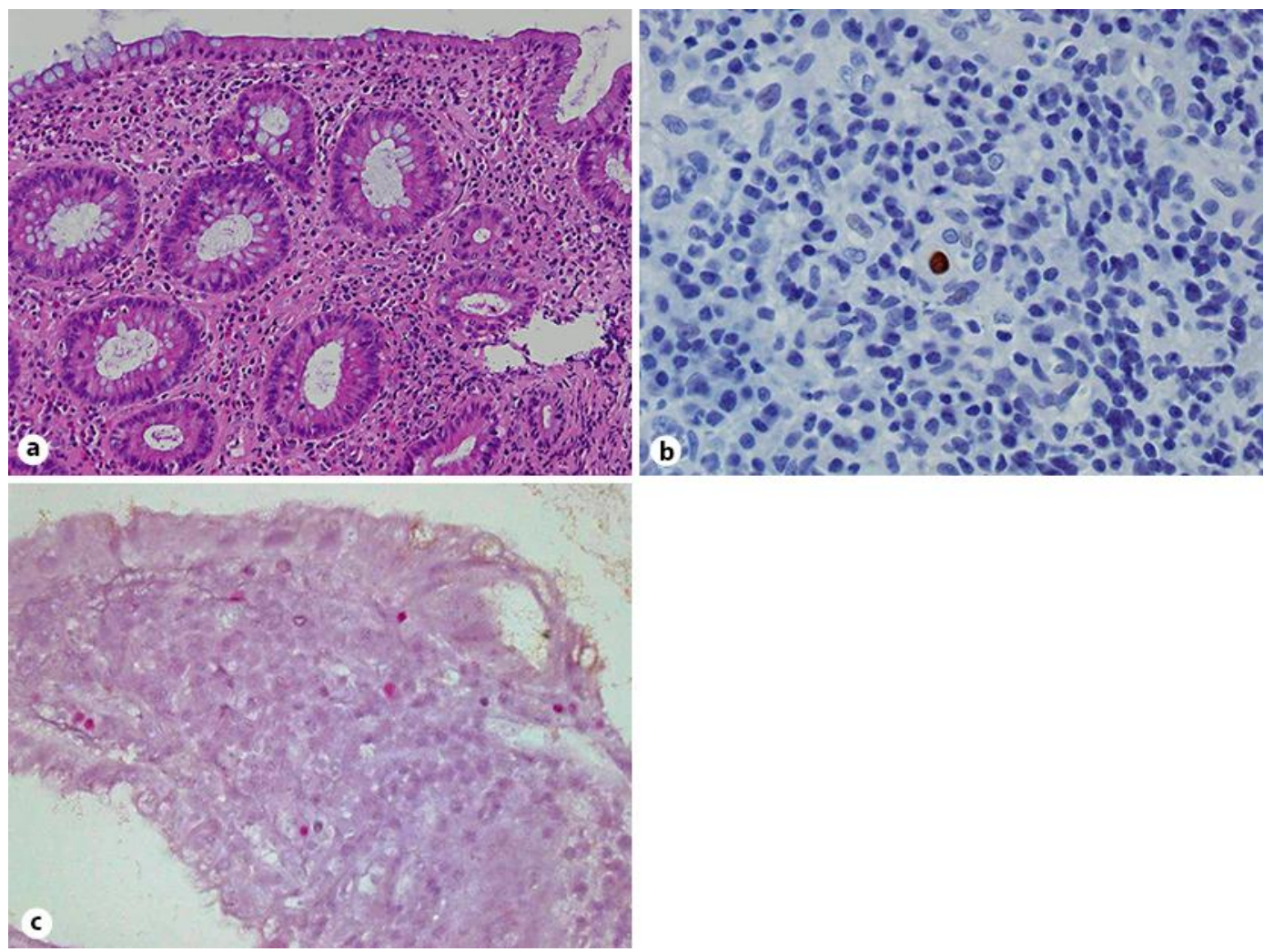

Fig. 2. Histological images of the colonic mucosa. a Diffuse lymphocytic infiltration of the lamina propria observed with hematoxylin and eosin staining $(\times 100)$. b CMV-positive cell in the lamina propria stained using CMV antibody $(\times 100)$. c In situ hybridization revealed EBV-encoded small RNA-1 (EBER-1)-positive cells $(\times 100)$. 